\title{
Actinolite as a proxy for characterizing the thermal evolution of Iron-Oxide Copper Gold deposits
}

IRENE DEL REAL ${ }^{1}$, MARTIN REICH ${ }^{2}$, ADAM SIMON $^{3}$, ARTUR DEDITIUS $^{4}$, FERNANDO BARRA ${ }^{1}$, MARIA ALEJANDRA RODRIGUEZ-MUSTAFA ${ }^{3}$ AND JOHN F.H. THOMPSON $^{5}$

${ }^{1}$ Universidad de Chile

${ }^{2}$ Universidad de Chile, Santiago

${ }^{3}$ University of Michigan

${ }^{4}$ Harry Butler Institute, Murdoch University

${ }^{5}$ Petrascience Consulting

Presenting Author: idelreal@gmail.com

Iron oxide-copper-gold (IOCG) deposits are a globally important source of $\mathrm{Cu}, \mathrm{Au}$ and critical commodities, including $\mathrm{U}, \mathrm{Co}$ and REE that are essential to sustain a carbon-neutral society. Despite their relevance, IOCG deposits remain an illdefined clan, with a range of characteristics that has complicated development of the general genetic model needed to guide exploration for new deposits. Here we focus, for the first time, on the mineral actinolite - an ubiquitous alteration phase in IOCG deposits - for temperature estimation at the mineral scale. We constructed novel grain-scale temperature images by computationally inverting compositional data from X-ray wavelength dispersive spectrometry (WDS) maps. This technique allowed visualization of inferred temperature gradients at a micro-scale within individual actinolite grains. Results show that Candelaria formed by the superposition of at least two mineralization events with a late $\mathrm{Cu}$-rich fluid $\left(\sim 550-700^{\circ} \mathrm{C}\right)$ overprinting an early, iron oxide-apatite (IOA) type mineralization event $\left(675-800^{\circ} \mathrm{C}\right)$. These distinct events were caused by episodic injections of magmatic-hydrothermal fluids from crystallizing magmas at depth. Our data provide the first empirical evidence of grain scale temperature gradients in an IOCG system, and supports the use of actinolite compositional variations as a novel approach to understand the formation of IOCG deposits, and a potential tool for vectoring in exploration.

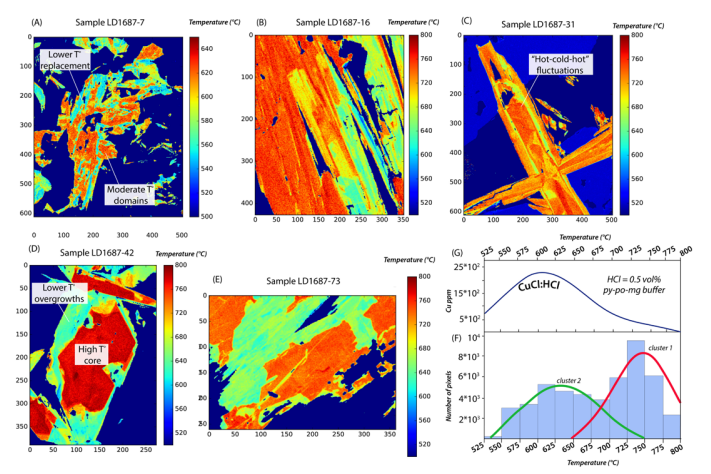

